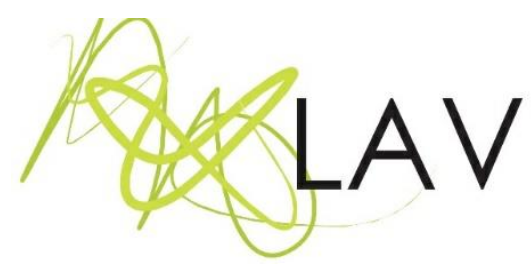

\title{
No rastro de narrativas maternas recolhi um fragmento de história que minha mãe contava sobre o meu nome
}

In the wake of maternal narratives I collected a piece of history that my mother said about my name

Luzia Renata Yamazaki ${ }^{\mathrm{i}}$ Universidade do Estado de Santa Catarina

\begin{abstract}
Resumo
Este artigo parte de uma narrativa materna relacionada à falsificação de meu nome, uma história que emerge do cotidiano da vida, mas beira a ficção. Com esse enfoque, colocase em questão a normativa patrilinear constante nos registros de nascimento e se rememora essa história individual para conectá-la a contextos sociais mais amplos. No processo de escrita, a partir de memórias pessoais, adota-se a abordagem metodológica por mônadas, utilizada por Walter Benjamin em Infância em Berlim por volta de 1900 (2000), um caminho possível para acolher a escrita fragmentária, que chega conduzida pelo hálito úmido do passado. Nessa perspectiva, a poética artística encontrou na fotografia a linguagem fundamental para dialogar com a escrita porosa que segue os ruídos das memórias.
\end{abstract}

Palavras-chave: narrativas, memórias, nome.

\begin{abstract}
This article comes from a maternal narrative related to the forgery of my name, a story that emerges from the everyday life, but is on the verge of fiction. With this focus, I question the patrilineal normative that is constant in birth records and I recollect this individual story to connect it to broader social contexts. When writing from my personal memories, I follow the methodological approach of monads, used by Walter Benjamin in Childhood in Berlin around the 1900s (2000), a way that enables welcoming the fragmentary writing that reaches the present lead by the moist breath of the past. In this perspective, the artistic poetics found in photography the necessary language to dialogue with a writing that follows the noises of memories.
\end{abstract}

Keywords: narratives, memories, name.

Enviado em: 16/11/19 - Aprovado em: 21/05/20

\section{O tear}

Em agosto de 2014, fiz uma viagem de carro com minha mãe. Nosso destino era o Buracão - o lugar de onde vim, em Londrina, no Paraná. No caminho, a paisagem, a 
estrada e nossa relação composta por entrelinhas. Falar e ouvir nossas próprias vozes que iam ao encontro do passado a partir do presente. Na estrada, uma frase de Clarice Lispector (1998, p. 16) me pega de surpresa: "O presente é o instante em que a roda do automóvel em alta velocidade toca minimamente o chão. E a parte da roda que ainda não tocou, tocará num imediato que absorve o instante presente e torna-o passado".

Nossa viagem durou cerca de dez horas, tempo suficiente para recriar nossas memórias apertadas em um carro em movimento. Nossas vozes esbarravam em fatos acontecidos, esquecidos, inventados, rememorados em pequenas situações, fragmentos que ganhavam relevo à medida em que o silêncio conquistava seu espaço.

A estrada cheia de curvas suportava caminhões em alta velocidade, e também o labirinto de nossas memórias. Subidas e descidas se revelavam apenas quando a neblina subia confundindo o asfalto com o abismo. Durante algum tempo, permanecíamos imóveis, como se estivéssemos ali apenas para seguir o fluxo dos outros veículos e de nossas memórias. Logo, atraídas por uma luz mais forte, seguíamos o caminho supostamente liso, deslizando sobre a estrada que nos levava de volta ao Buracão.

Ainda sob efeito da neblina que esconde a superfície e as margens, continuamos nossa viagem provocando conversas sobre a vida, as memórias, as marcas e marcos que nos afetam. E, por mais que obscurecessem as coisas por detrás das margens, a neblina, assim como as narrativas, trouxeram relatos reais e imaginários que se entrelaçaram no emaranhado de nossas conversas fragmentadas.

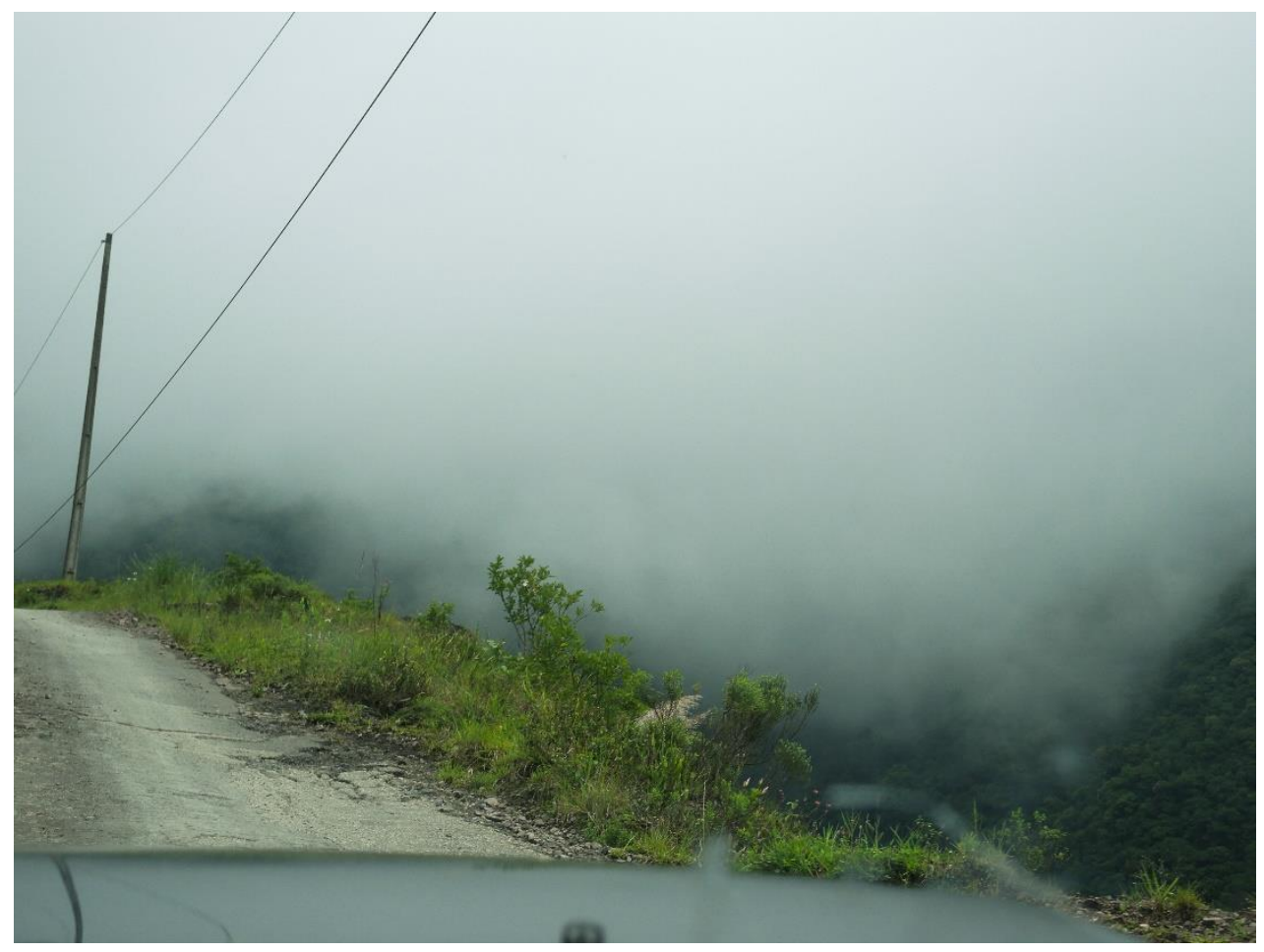

Revista Digital do LAV - Santa Maria - vol. 13, n. 2, p. 312 - 325 - mai./ago. 2020 ISSN 1983 - 7348 
Figura 1: Abismos

Fonte: a autora, 2014

Ao chegar ao nosso destino, entrei pela primeira vez na casa que cresci depois de vinte anos. Como era possível que ela fosse tão pequena? É bonito quando nos deparamos com a percepção infantil que ainda mora em nós, ela faz as coisas que nos completavam na infância encolherem, ou se alargarem para depois se juntarem à lembrança dos brinquedos. A rua, assim como a casa, também encolheu. Encolheram também as distâncias entre os muros, entre mim e minha mãe, realidade que me fez entender a intensa vida coletiva que ultrapassava as paredes das casas tornando íntimo os rumores da vida privada.

Fotografei a casa vazia, porque queria captar seus segredos. Toda casa tem um segredo, a minha guarda muitos. E todos estão lá, presos na parede mal pintada que ainda expõe as raspas de tinta que eu tirei com minha unha de criança. Ao abrir a porta, ao pisar no assoalho de madeira, ouvi o mesmo rangido de antigamente. A pausa do tempo cronológico deu lugar ao tempo vertiginoso das memórias que não se deixam capturar. Cenas que se passaram naquele lugar ultrapassaram o cotidiano ordinário e me alcançaram no presente com uma potência desconhecida.

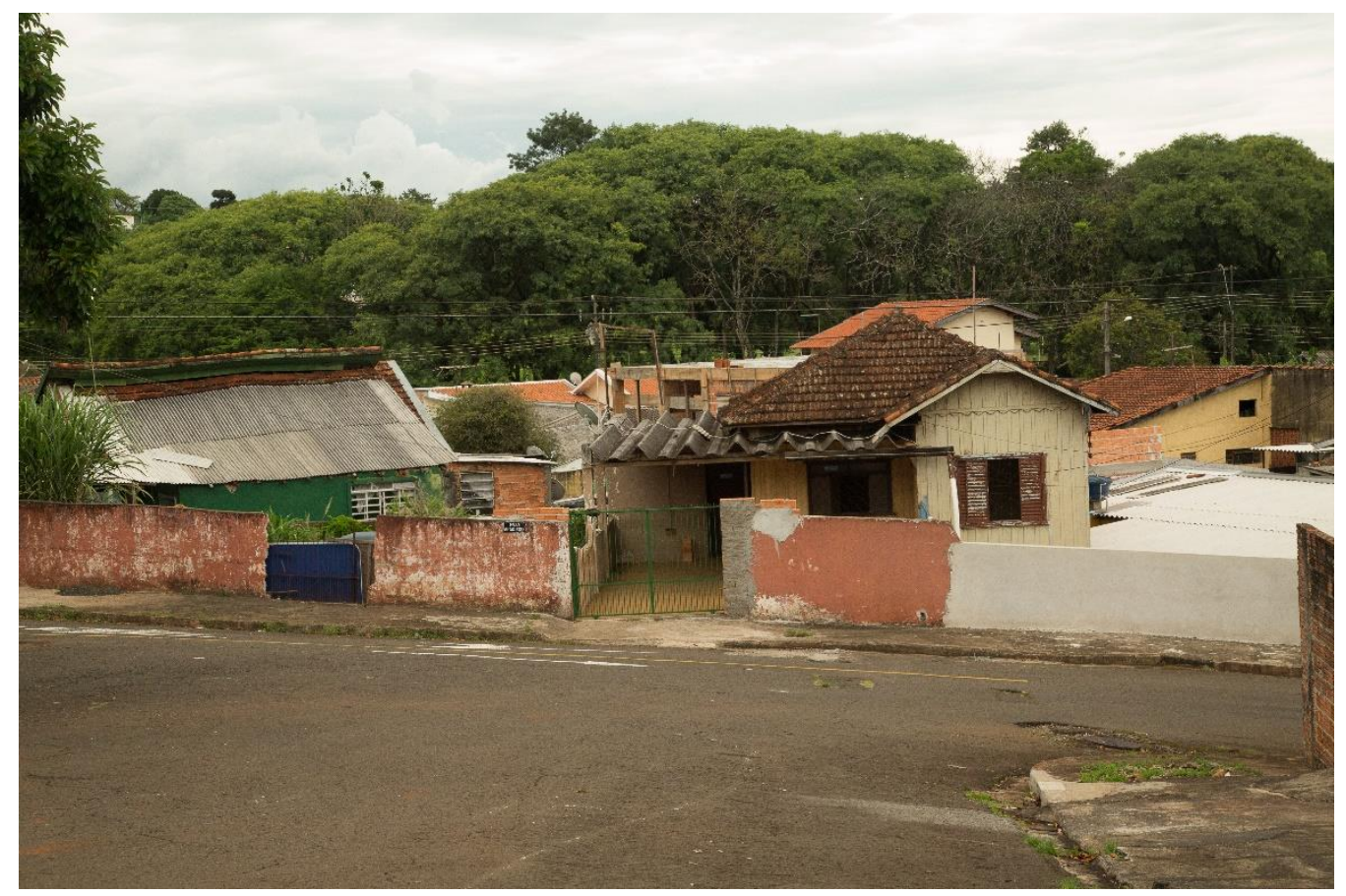

Figura 2: Minha casa em ruína Fonte: a autora, 2014 
Soube por uma vizinha que os inquilinos haviam se mudado um dia antes de minha chegada, seus vestígios ainda habitavam a casa sob a forma de louças rejeitadas, brinquedos quebrados, bonecas sem braço, objetos que povoam as casas, e a minha também, no ontem e no hoje. Registrei seu silêncio, desenhei suas imperfeições, rememorei as narrativas contadas pela minha mãe na beira da cama, a qual só cabia naquele canto do quarto que outrora foi gigante.

Por dois dias, tentei habituar meu corpo àquele lugar estranhamente íntimo. No silêncio da casa, ouvi o portão ranger. Uma amiga chegava com duas meninas de aproximadamente sete anos. Enxerguei a mim nelas e vi seus corpos ganharem o espaço que meu corpo ocupava quando eu era a criança que ali brincava. Por um instante, elas eram eu, virando cambalhota no assoalho de madeira. Estar ali era como poder olhar o trabalho do tempo: a casa em ruínas, crianças brincando na minha infância, na casa de minha infância.

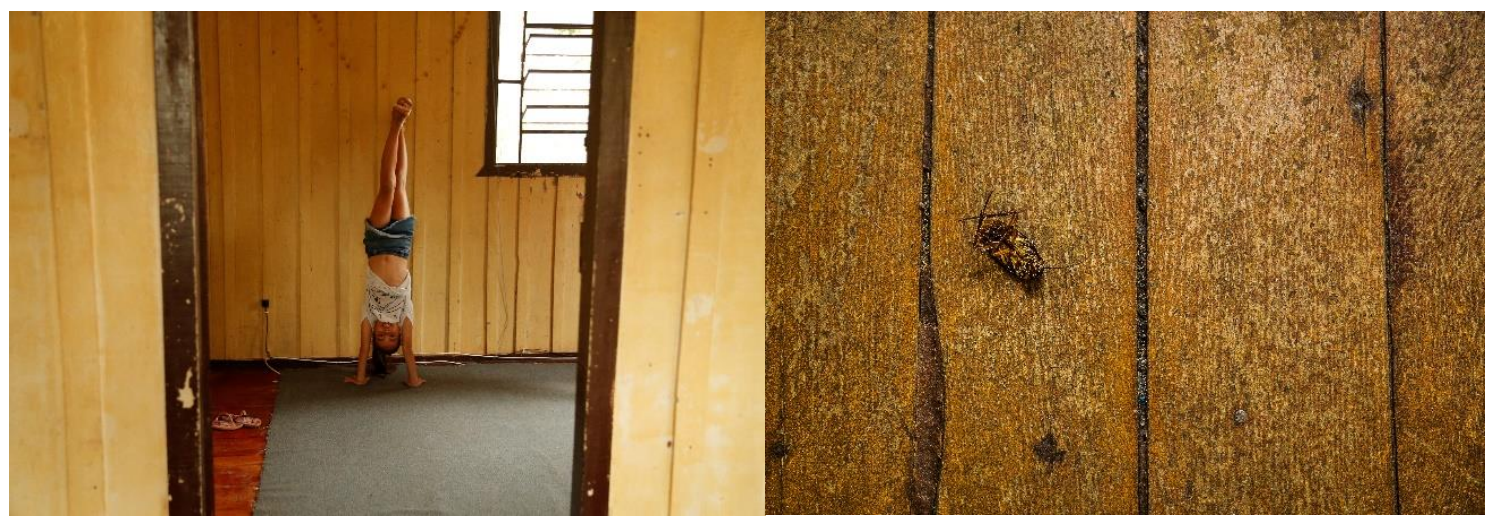

Figura 3: Vertigem.

Fonte: a autora, 2014.

\section{Os fios}

Seguir os fios apontados por - eu criança - esboça a construção de uma narrativa política feita de detalhes, texturas e camadas escondidas. Em seus movimentos descompassados, a criança memória transita pela casa sem saber ao certo qual seu lugar. Sensibiliza-se com os espaços, com as frestas, com os escuros e com as sombras, inventa esconderijos, provoca limites estabelecidos e tensiona as certezas. Pego na mão da criança que fui para rememorar o passado como possibilidade de transformação, nas palavras de Benjamin, "redenção" (2012). Essa seria a função política da rememoração, a tomada da palavra crítica a partir do presente como possibilidade de redenção. 
Em meu incômodo, rememoro como possibilidade de questionar a estrutura patrilinear que levou minha mãe a falsificar meu nome no registro de nascimento, uma estratégia de legitimação criada para não deixar em branco o espaço ocupado pelo nome do pai.

O (I)reconhecimento paterno desencadeou na inclusão do nome de Selvino José da Silva, um pai registral desconhecido que legitimaria minha existência. Uma atitude ambivalente de minha mãe que, ao mesmo tempo em que se alinha ao discurso patriarcal, burla o sistema por dentro e falsifica minha identidade em um cartório de ofícios.

O gesto ambivalente de minha mãe, de seguir a normativa patrilinear e burlá-la, resulta de um jogo de forças entre opostos extremos. Ela sabia que me criaria sozinha e mesmo assim, simbolicamente, imaginou que o nome de homem poderia salvaguardar a criança de possíveis preconceitos sociais. A seu modo, atendeu ao sistema, mas o blefou, fazendo com que esse me incluísse, ainda que pela falsificação. Em outras palavras, avistamos as tensões escondidas naquela época se revelarem no agora.

Histórias desimportantes. Ao escrever, a partir de minhas memórias pessoais, observo em meu nome a possibilidade de questionar normativas que orientam nosso estar no mundo sob um sistema de dominação masculina. Nessa perspectiva, a arte e os conceitos teóricos são ferramentas utilizadas a favor de uma discussão menos pessoal e mais política da sociedade na observação de suas normas e condutas frente ao enquadramento de mulheres.

Nesta escrita, reporto-me ao lugar de onde vim e com quem convivi na infância o Buracão, minha mãe, meu nome, minha casa, meu quarto. Às narrativas maternas, entreteço minhas memórias, misturando a criança que fui à mulher que sou, pois elas escrevem juntas no tempo oportuno das lembranças e esquecimentos como se fosse possível transitar por lugares distintos dentro das mesmas memórias. Nessa tessitura formada por singularidades, o que é íntimo se torna fonte de produção de conhecimento ao ser relacionado a um contexto social mais amplo (BENJAMIN, 2009).

Ao estruturar este texto, busquei por uma abordagem metodológica em que fosse possível trazer os fragmentos de minhas memórias de infância como imagens provocadoras de sentidos. Nesse caso, a obra Infância em Berlim por volta de 1900 (2000) - em que Walter Benjamin rememora sua infância revestida de imagens políticas, 
foi uma importante leitura para que eu pudesse desenvolver um pensamento fundamentado na abordagem metodológica por mônadas ${ }^{1}$ - miniaturas de memórias.

$\mathrm{Na}$ obra referida, ao chamar por sua criança, o filósofo oferece a ela brinquedos de gente grande. Em outras palavras, a criança Benjamin possibilita o despertar de uma rememoração política do homem Benjamin em um contexto de fragmentação social que se fortalecia na modernidade europeia.

A seguir, escrevo a narrativa/mônada denominada (I)reconhecimento, que está ornada com estampas do presente e, em sua paralização, cristaliza imagens que apresentam rastros do vivido, misturados a questões sociais mais amplas:

\section{(I)reconhecimento}

Algumas cidades são como labirintos, entrar nelas sem um fio de Ariadne para encontrar a saída pode ser uma aventura que poucos conseguem realizar com êxito. Quando grávida minha mãe entrou num desses labirintos, tempos depois se viu perdida e quis sair comigo nos braços, mas era impossível, pois me faltava o registro de nascimento. Constrangida em deixar em branco o nome de pai, minha mãe, que antes de se organizar se desorganizava, me registrou com o nome de um desconhecido, pois em suas crenças, o nome de um homem legitimaria minha existência. Hoje, carrego em meu nome o Silva de um tal Selvino, cuja mãe é Belarmina. Um pai e uma avó que se inscrevem em meus documentos, deixando rastros do que estava presente no pensamento de minha mãe que só queria sair daquela cidade que cansa.

Luzia Renata da Silva é meu nome nos registros oficiais. Com estranhamento, carrego em meu nome o de um desconhecido, Selvino José da Silva. Na época, minha mãe imaginou que tal falsificação pudesse diminuir o possível mal-estar que a ausência do nome paterno no registro de nascimento pudesse causar à criança. Seria essa ausência um marcador social negativo em meados de 1970?

Com base nessa pergunta, teço uma reflexão a partir da mônada (I)reconhecimento para compreender quais discursos operaram no procedimento de minha mãe que visou o cumprimento de normativas pedagógicas presentes no discurso

\footnotetext{
${ }^{1}$ Em suas elaborações monadológicas, Benjamin se inspirou em Gottfried Wilhelm Leibniz, matemático alemão do século XVII. Para maiores informações, indico o site Leibniz Brasil: < https://leibnizbrasil.pro.br/leibniztraducoes/monadologia.htm>. A abordagem metodológica por mônadas vem sendo sistematizada pelos grupos de pesquisa 'Kairós: educação das sensibilidades, história e memória', da Universidade Estadual de Campinas UNICAMP, liderado por Maria Sílvia Duarte Hadler e Arnaldo Pinto Junior; o 'Pameduc: patrimônio, memória e educação', liderado pelos professores Elison Paim e Clarícia Otto, da Universidade Federal de Santa Catarina UFSC; e o grupo 'Rastros: história, memória e educação', liderado por Elison Paim e Maria de Fátima Guimarães, na Universidade de São Francisco - UFS. Os três grupos estão relacionados a pesquisas realizadas no âmbito da educação. Nessa linha de pesquisa, teses e dissertações foram defendidas tendo como objetivo construir experiências coletivas no estudo das memórias e sua relação com a educação. Por intermédio do professor Elison Paim, participei do curso Imagens de produção de conhecimentos históricos-educacionais em Walter Benjamin, ministrado pela professora Cyntia Simioni França na Universidade Federal de Santa Catarina UFSC, Florianópolis, ocasião em que pude visualizar a estrutura desta tese tendo como base a abordagem citada.
}

Revista Digital do LAV - Santa Maria - vol. 13, n. 2, p. 312 - 325 - mai./ago. 2020 ISSN 1983 - 7348 http://dx.doi.org/10.5902/1983734841162 
patriarcal, especialmente a que traça a linhagem dos filhos a partir da figura paterna. Nas ações de minha mãe, os vestígios do patriarcado a levou a crer que, para legitimar minha existência, seria preciso agregar aos nossos nomes o nome de um desconhecido que estava ao acaso do tempo, pois, em seu pensamento, o nome de um homem salvaguardaria a criança de possíveis preconceitos sociais moldados nos discursos da nação.

A falsificação de meu nome é uma reorganização que emerge da prática da vida. Nessa trama, minha mãe tenta se alinhar a uma normativa social que diz que o nome do pai é mais importante que o nome da mãe. Com essas certezas, minha mãe ajusta minha certidão de nascimento burlando o sistema por dentro. Seria como uma escrita nas fissuras onde é possível ler obediências/desobediências, negação/reinvenção de tradições nos processos de deslocamentos e construção de identidades que contam histórias e comunicam ruídos existentes na imprecisão do cotidiano de sujeitos que vivem no entre lugar (BHABHA, 2014).

Mas quem é Selvino José da Silva? - um outro no entre lugar, um viajante, andarilho, refugiado, escravizado. Um homem na multidão, um flâneur, solitário, perambulando pelas ruas de São Paulo, mirando a intensa verticalização da cidade. Gosto de pensar em Selvino como uma versão latina e tardia do flâneur parisiense de Charles Baudelaire. Essa figura simbólica da modernidade europeia que passava seus dias a vagar pelas ruas, observando o movimento, as vitrines, as pessoas, as paisagens urbanas que o embriagavam e distraiam. Benjamin o nominou de botânico do asfalto, aquele que tem intimidade com a paisagem (1994, p. 34), que se mistura ao asfalto, que vê a cidade e se vê na cidade.

A rua se torna moradia para o flâneur que, entre as fachadas dos prédios, sente-se em casa tanto quanto o burguês entre suas quatro paredes. Para ele, os letreiros esmaltados e brilhantes das firmas são um adorno de parede tão bom ou melhor que a pintura a óleo no salão do burguês; muros são a escrivaninha onde apoia o bloco de apontamentos; bancas de jornais são suas bibliotecas, e os terraços dos cafés, as sacadas de onde, após o trabalho observa o ambiente (BENJAMIN, 1989, p. 35).

São Paulo se agiganta aos olhos dos Selvinos que, ao flanarem, ouvem os ruídos da metrópole que range aos sons da modernidade capitalista, enquanto esta mastiga seus habitantes mais ocultos. Os mendigos, os farrapos, os poetas, as prostitutas e todos aqueles e aquelas que não se enquadram, e nem querem se enquadrar, nas engrenagens da modernidade, são incluídos perversamente no sistema.

Baudelaire pensava a figura do flâneur como um burguês que tem o tempo a sua disposição e, para o horror da sociedade capitalista, desperdiça. Leio Selvino como um 
flâneur latino que usa seu tempo e seu espaço desperdiçado em idas e vindas errantes na multidão que o transpassa, um migrante em deslocamento, um observador embriagado na multidão do abandono moderno.

Selvino, errante da metrópole brasileira, não era burguês como o flâneur de Baudelaire, pois sua classe social está impressa em seu ato, um passante na história de minha mãe. Ao me registrar, registrou um imaginário em mim.

\section{A uma passante}

A rua em derredor era um ruído incomum, longa, magra, de luto e na dor majestosa, Uma mulher passou e com a mão faustosa Erguendo, balançando o festão e o debrum; Nobre e ágil, tendo a perna assim de estátua exata. Eu bebia perdido em minha crispação No seu olhar, céu que germina o furacão, A doçura que embala o frenesi que mata. Um relâmpago e após a noite! - Aérea beldade, E cujo olhar me fez renascer de repente, Só te verei um dia e já na eternidade? Bem longe, tarde, além, jamais provavelmente! Não sabes aonde vou, eu não sei aonde vais, Tu que eu teria amado - e o sabias demais! (Baudelaire)

A passante Conceição não passava só, porque carregava uma criança no colo, e ao invés de esvoaçante com a mão faustosa nos ornamentos de seu vestido, pausava o passo no reconhecimento de Selvino. Não ofereceu seu amor, tampouco um encontro na eternidade, mas sim uma proposta improvável: ser pai registral de uma criança desconhecida, dar-lhe seu nome, sua descendência, seus trapos, sua indiferença, para depois, novamente, perder-se na multidão, na rapidez dos tempos modernos. Assino Silva de Selvino, um caminhante.

\section{Arremate}

Ao rememorar as narrativas de minha mãe, entrelacei essa escrita a um processo artístico onde fotografias, documentos, bilhetes e objetos foram revisitados. Entre os espaços espremidos que separam os papéis, um novo ar passou a circular, trazendo outra vida para as imagens esquecidas, borradas, amassadas. Desencaixotamos suas lembranças e olhamos para as superfícies das fotografias como quem olha para fatos acontecidos ficcionalizados no tempo presente. Nos fios da conversa, foi "necessário invocar a musa da narrativa, a faculdade épica por excelência, a Mnemosine, deusa 
grega da memória, invocando a rememoração como atividade artesanal e produtora de conhecimentos" (SANTANA, 2017, p. 125).

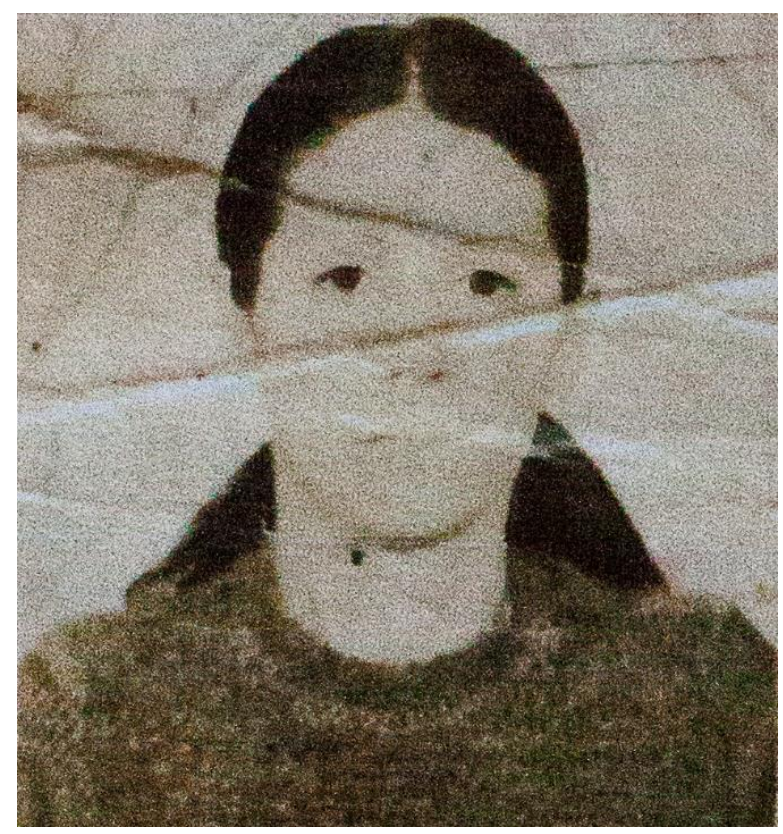

Figura 4: Sem título

Fonte: a autora, 2014

No material encontrado, as memórias em reboliço, tudo parecia participar da mesma (des)ordenação familiar. Os documentos, as fotografias e os registros de suas vivências estavam acumulados em uma caixa empoeirada sobre o guarda-roupa à espera de uma visita. Revirar esses arquivos significou atrasar os ponteiros do relógio um segundo antes da hora-memória. Da pequena caixa, roubei as sobras, peguei as imagens rejeitadas que moravam no fundo, as que se escondiam sob as escrituras desimportantes já sem o calor de mãos familiares. Queria as imagens desprezadas, amassadas e rasgadas no esquecimento.

Ao tomá-las do esquecimento, iniciei uma prática artística onde seu rosto fragmentava-se, transformava-se como se ela pudesse atravessar as camadas do papel como quem se atravessa nas histórias arranjadas. Ela era o desvio, aquilo que não se encaixa, que se tece na precariedade. Aspectos de suas memórias-imagens potencializam as narrativas e sobrevivem por meio de uma imagem rastro. 


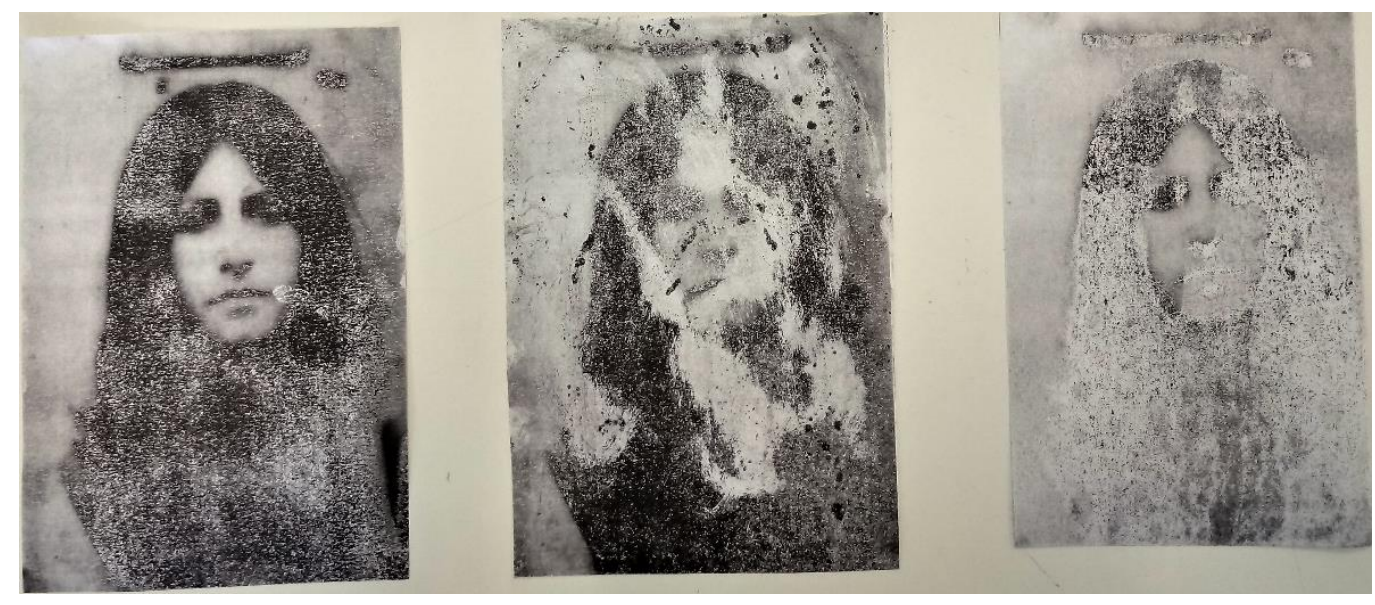

Figura 5: RastrosRostos

Fonte: a autora, 2019

Seu rosto não poderia trazer a nitidez da fotografia, pois acredito que as memórias são também ruínas, escapam-nos, e metáfora alguma dá conta de dizê-las em sua totalidade. Aqui, palavra e imagem se conectam na criação de uma estrutura narrativa ficcional e imprecisa que toca no passado com os olhos do presente. Assim, como Jeanne Marie Gagnebin sublinha, acredito que na "construção que remete a uma noção de verdade não mais como exatidão da descrição, mas sim, muito mais, como elaboração de sentido, seja ele inventado na liberdade da imaginação ou descoberto na ordenação do real" (GAGNEBIN, 2005, p. 68).

Transformo as imagens tirando delas na nitidez precisa de seus contornos, do mesmo modo, transformo as narrativas de minha mãe em mônadas, pois é disso que se tratam a memória: do refazimento no presente.

Nos dias de hoje, observo a imagem revelada pela prata acinzentada, que congrega em sua composição elementos como a luz, a escuridão, a interrupção e a fixação - elementos físicos e químicos definidores da invenção da fotografia que, em essência, congela fragmentos de segundos de nossa existência efêmera deixando em aberto infinitas possibilidades de leituras, pois o congelamento da imagem não significa imobilidade, mas movimento e, por vezes, movimentos de memórias tensionados entre passado e presente, particular e coletivo.

Com todas as incertezas que isso possa significar, o ato de narrar ajuda a lembrar quem somos. Narramos com palavras, com imagens, com a cultura. Narramos como forma de produção de conhecimento, como ato político, para encontrar e metaforizar outras memórias.

A imagem matriz para essa prática foi uma foto preto e branca $3 \times 4$, grampeada em uma carteirinha do Instituto Nacional de Assistência Médica da Previdência Social - 
INAMPS. A carteirinha gastada pelo tempo ainda tem as marcas de ferrugem do grampo e revela a classe social de minha mãe. Scaneei a foto, realizei um trabalho de tratamento na imagem e a transferi para a pedra da lito. Com essa imagem, realizei também a técnica do transfer, da costura e da encáustica. A cada impressão, convencia-me de que os acasos agem nos intervalos do tempo. Tempo da reimpressão, tempo da memória.

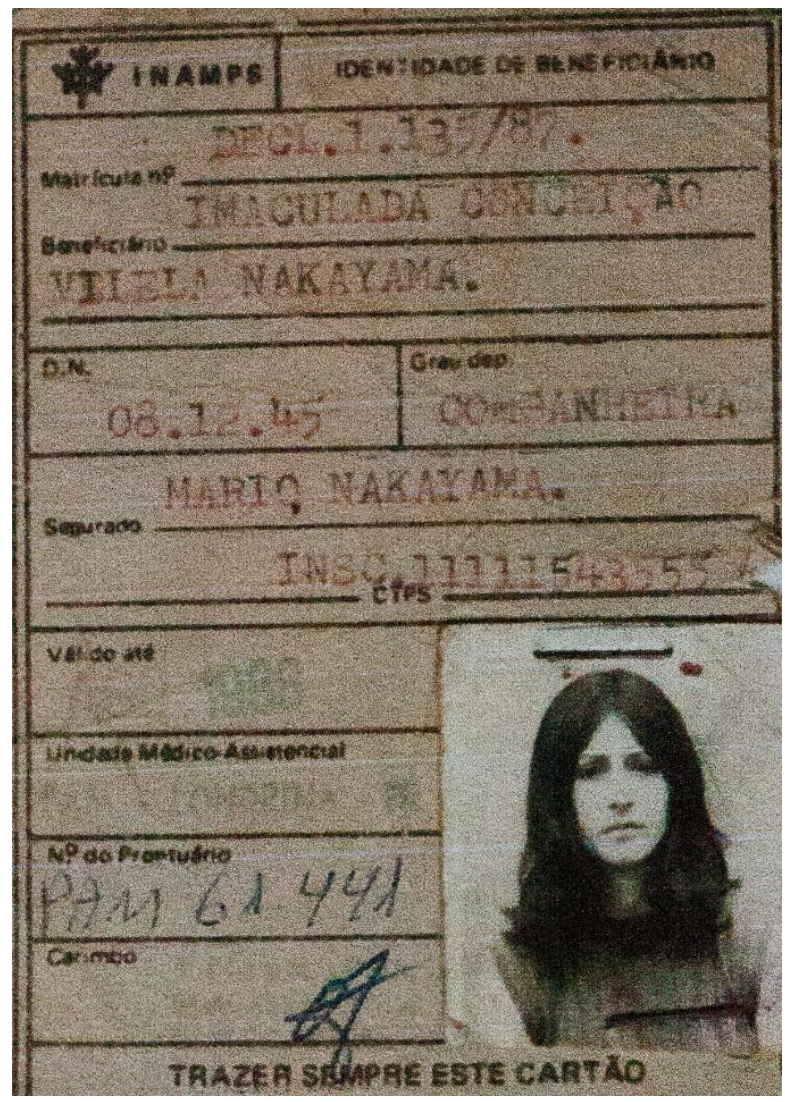

Figura 6: Arquivo pessoal.

Fonte: a autora, 2019.

Que sopro de vida trazem essas imagens retidas no espaço de uma foto? No álbum de família, esse objeto empoeirado que guarda as coleções de acontecimentos, o que diziam as vozes que se perderam no ato do congelamento da imagem? Para onde foram todos depois do clic? Viramos suas páginas silenciosamente e, nesse gesto, vemos o passar do tempo impresso nas imagens desgastadas, na ausência de contraste, nas manchas do fixador mal lavado que data a fotografia ampliada e revelada por processos anteriores à impressão a jato de tinta.

Os processos deixam suas marcas e marcos, assim como o tempo, que esconde, em suas cavidades, aromas captados nos lugares mais recônditos de nossa imaginação. Essa, por meio da linguagem, recebe e emite os vestígios daquilo que não existe mais como existiu da primeira vez. 
Nessa trama, a estrutura ficcional e imprecisa que construí, por meio de minhas memórias, entrelaça-se às imagens de arquivos fotográficos de minha família e de livros de arte como se fossem todos pertencentes a uma mesma estante. O modo de operar está intimamente relacionado à produção de sentidos. O transfer ${ }^{2}$ oferece a possibilidade da inversão, como em uma leitura realizada diante do espelho, as imagens/palavras alteram sua posição referencial, tornam-se invertidas e, em uma primeira mirada, ilegíveis. Para realizá-las, fotocopiei a imagem para um papel sulfite, o qual mergulhei em um componente químico solúvel e os imprimi em prensa de gravura em metal. Por meio desse procedimento, consegui imagens que se formam, mas também se deformam, mancham, não são nítidas e alteram seus tamanhos e evidenciam a precariedade das memórias.

O processo artístico, em suas impurezas, mistura fotografia, transfer, litografia, carimbo e encáustica na conformação de um trabalho que revela meu incômodo frente ao discurso opressor que sobrevive nas entrelinhas das sociedades patriarcais. Nesse sentido, desenvolvo uma série de trabalhos usando documentos e fotografias de arquivos pessoais para pensar como, através de pesquisas em artes, podemos construir imagens políticas provocadoras de sentidos para, assim, contribuir com o debate acerca da arte e das questões referentes à mudança do paradigma social que coloca os homens em uma relação privilegiada em relação às mulheres.

\section{Referências}

BARTHES, R. A câmera clara: notas sobre a fotografia. Rio de Janeiro: Nova Fronteira, 1984.

BARROS, M. Memórias inventadas: a segunda infância. São Paulo: Planeta, 2006.

BENJAMIN, W. Magia e técnica, arte e política: ensaios sobre literatura e história da cultura. Obras escolhidas I. São Paulo: Brasiliense, 2012.

BENJAMIN, W. Infância em Berlim por volta de 1900. In: Rua de mão única. Obras escolhidas v. 2. São Paulo: Editora Brasiliense, 2000.

BENJAMIN, W. Charles Baudelaire um lírico no auge do capitalismo. Obras escolhidas III. 3. ed. São Paulo: Brasiliense, 1994.

BENJAMIN, W. O regresso do flâneur. Baudelaire e a modernidade. Tradução de João Barrento. Belo Horizonte: Autêntica, 2015.

BHABHA, H. O local da cultura. Belo Horizonte: Editora UFMG, 2013.

2 Técnica de transferência de imagem por meio de processo químico.

Revista Digital do LAV - Santa Maria - vol. 13, n. 2, p. 312 - 325 - mai./ago. 2020 ISSN 1983 - 7348 
BHABHA, H. Questão outra. Entrevista concedida à 30 Bienal de São Paulo: A iminência das poéticas (2012). Disponível em: <https://www.youtube.com/watch?v=ym2dPYqIvmA>. Acesso em: 04 abr. 2019.

CASTRO, M. G.; LAVINAS, L. Do feminino ao gênero: a construção de um objeto. In: COSTA, A. de O.; BRUSCHINI, C. Uma questão de gênero. Rio de Janeiro: Rosa dos tempos, 1992.

DIAS, A. N. Demografia histórica e os registros paroquiais: possiblidades para o estudo da família norte mineira no século XIX. XXVII Simpósio nacional de história, ANPUH. Natal, $2013.2 \quad$ Disponível em: <http://www.snh2011.anpuh.org/resources/anais/27/1364940730_ARQUIVO_ANPUHRESUMO.pdf >. Acesso em: 12 abr. 2019.

FRANÇA, C. O canto da Odisseia e as narrativas docentes: dois mundos que dialogam na produção do conhecimento histórico-educacional. Campinas: UNICAMP, 2015, p. 249. Tese (Doutorado), Programa de Pós-graduação em Educação, Universidade Estadual de Campinas, 2015.27 Disponível <http://repositorio.unicamp.br/jspui/handle/REPOSIP/321385>. Acesso em: 27 jul. 2017.

GAGNEBIN, J. M. Sete aulas sobre linguagem, memória e história. Rio de Janeiro: Imago, 2005.

GALZERANI, M. C. B. Memória, história e tempo: perspectivas teórico-metodológicas para a pesquisa em ensino de história. Revista Cadernos do Ceom, v. 21, n. 28, p. 15$32,2008$.

GERLICH, R. Criação do patriarcado: como aconteceu? Arquivo radical. Disponível em: <https://medium.com/arquivo-radical/cria\%C3\%A7\%C3\%A3o-do-patriarcado-comoaconteceu-afbab45a9438>. Acesso em: 28 abr. 2019.

HALL, S. A identidade cultural na pós-modernidade. Rio de Janeiro: DP\&A, 2006.

LANCRI, J. O meio como ponto zero. In: BRITES, B.; TESSLER, E. (orgs.). Metodologia da pesquisa em artes plásticas. Porto Alegre: Editora UFRGS, 2002.

LEIBNIZ, W. Princípios da filosofia ou a monadologia. Disponível em: <https://leibnizbrasil.pro.br/leibniz-pdf/monadologia.pdf>. Acesso em: 22 abr. 2019.

LERNER, G. La creación del patriarcado. Barcelona: Editora Crítica, S. A. Aragó, 1990.

LISPECTOR, C. Água Viva. Rio de Janeiro: Rocco, 1998.

PAIM, E. A. Rememorações de professores de história: Expectativas quanto à formação inicial. Fóruns Contemporâneos de Ensino de História no Brasil, 2013.

SEIXAS, J. Percursos de memórias em terras de história: problemáticas atuais. In: BRESCIANI, S.; NAXARA, M. (orgs). Memória e (re)sentimento: indagações sobre uma questão sensível. Campinas: Editora da Unicamp, 2001.

SANTANA, T. M. Narrativas femininas Guajajara e Akrãtikatêjê no ensino superior. (Dissertação) Programa de Pós-Graduação em Educação, na linha História e Sociologia, Universidade Federal de Santa Catarina - UFSC, 2017. 
i Artista/professora/pesquisadora com mestrado e doutorado em Artes Visuais pela Universidade do Estado de Santa Catarina na linha de pesquisa Processos Artísticos Contemporâneos. Graduação em Educação Artística, especialização em Fundamentos da Arte na Educação pela FAP-Curitiba. Tem ministrado oficinas de fotografia pinhole, construção de câmera escura, fotografia analógica, fotografia contemporânea e história da arte. Coordenou Cinco Edições do Festival de Fotografia Floripa na Foto, e por dois anos foi professora e coordenadora do Núcleo de Estudos em Fotografia e Arte - NEFA / Florianópolis.

Como citar esse artigo:

YAMAZAKI, Luzia Renata. No rastro de narrativas maternas recolhi um fragmento de história que minha mãe contava sobre o meu nome. Revista Digital do LAV, Santa Maria: UFSM, v. 13, n. 2, p. 312-325, mai./ago. 2020. 